\title{
Social Impacts of International Sport Events - Based on Experiences from European Youth Olympic Festival 2017 Győr
}

\author{
By Tünde Máté*
}

\begin{abstract}
Social impacts of international sport events can be defined as the way the sport events changes the collective and individual values, pattern of behaviour, structure of the community, the way and quality of life. The paper looks into the opportunities and ways to involve the citizens of the organizing city and making them committed towards the international sport events. Additionally it seeks answers to the question, how sport facilities related to European Youth Olympic Festival (in the following EYOF) could increase the sport economic activity of the City of Györ? Between 1998 and 2002 and especially since 2010, the Hungarian Government handles sport as a priority strategic sector. During the planning phase of EYOF one of the main goals evolved was the widespread inclusion of the citizens of Györ. In case of the infrastructural investments and facilities they were not just built for the EYOF but for post utilization. The objective of post utilization is to increase the medium and long term participation of the citizens of Gyor, and thus serve health prevention. The quantitative study consisted two surveys with the participation of 1337 residents of Györ. The results of the research taken before and after the event, showed the change in the citizen's perception towards EYOF in accordance of their experiences during the event. The qualitative research included interviews with professionals and field-research. In the study we identified the implemented actions of the organizing city in order to involve the urban population as much as possible. In case of infrastructural investment we investigate if there was any improvement in the sport activity of citizens.
\end{abstract}

Keywords: health-preservation, health-promotion, international sport event, social impacts.

\section{Introduction}

Social impacts of international sport events can be defined as the way sport events change the collective and individual values, pattern of behaviour, structure of the community, the way and quality of life (Task 2013).

This paper looks into opportunities and ways to involve the residents of the host city and to make them committed to international sport events. Additionally, it seeks answers to the question how sport facilities related to EYOF could increase the sport economic activity of the city of Györ and whether they are able to become a determining factor of the health economy.

Since the late 1990s, in addition to the previous Olympic-centric approach, Hungary has seen a stronger display of the preventive and health promotion function of sport (Gyömörei 2012). Between 1998 and 2002 the Hungarian

*PhD Candidate, Széchenyi István University, Hungary. 
Government treated, and since 2010 it has increasingly considered sport as a priority strategic sector, and has given governmental funding to projects related to international sport events (construction of sport facilities and urban rehabilitation).

In case of national sport events, complex long-term and strategic thinking is crucial (András and Kozma 2014). During the planning phase of EYOF one of the main goals that were proposed was the large-scale involvement of the residents of Györ in order to make them committed to EYOF and also to create strong links between the urban development goals and the event.

As far as the infrastructural projects and facilities are concerned, they were built not exclusively for EYOF, but rather for post-utilization. The objective was to increase the medium- and long-term participation of the residents of Györ, and thus serve preventive health programs. The infrastructure is dedicated to public sport and to serving disease prevention and health promotion goals.

The quantitative study consisted of two surveys with the participation of 1,337 local residents. The results of the research conducted before and after the event showed a change in the residents' perception of EYOF based on their own experience gained during the event.

The qualitative research included interviews with professionals and field-research. In the study we identified the actions implemented by the host city in order to involve the urban population as much as possible.

In the case of infrastructural projects we investigated the use of sport facilities by the general public in the first year after the event and the improvement in the residents' sport activity, if any.

The study and the involved research based on the draft version of my dissertation called as Acceptance of the impacts of international sport events by the residents from organizing city, recognition and its importance - based on the European Youth Olympic Festival 2017 in City of Győr (Máté 2017).

\section{Literature Review}

\section{Social Impacts}

Social impact refers to the manner in which a sport event generates changes in the collective and individual value systems, behaviour patterns, community structures, lifestyle and quality of life (Taks 2013). Three main aspects of social impact can be identified (Taks 2013):

$\rightarrow$ Sport and sport participation: the degree to which sport events stimulate the sport sector and especially stimulate participation in sport;

$\rightarrow$ Attitudes and beliefs: the degree to which sport events influence people's beliefs, attitudes, norms and values (e.g. pride, happiness, "feeling good");

$\rightarrow$ Social cohesion: social cohesion is the ongoing process of developing a community of shared values, shared challenges and equal opportunities, based on a sense of trust, hope and reciprocity. 
The article written by B. Knott, K. Swart, S. Visser (2015) provides reflections on the 2010 FIFA World Cup, on the event's consequences and its impacts on the quality of life for host city residents. The authors divided the social and cultural impacts (Table 1) into positive and negative ones based on the following literature: Burnett (2008), Ohmann et al. (2006), Kim and Petrick (2005), Saayman (2001), Chalip (2006) and Chain (2009).

Table 1. Socio-Cultural Impacts of Sport Mega-Events Impacting Quality of Life for Residents

\begin{tabular}{|l|c|}
\hline \multicolumn{1}{|c|}{ Socio-cultural impacts of sport mega events impacting quality of life for } \\
residents
\end{tabular}

Source: Pursuant to Knott - Swart - Visser 2015, Burnett (2008), Ohmann et al. (2006), Kim and Petrick (2005), Saayman (2001), Chalip (2006); and Chain (2009). 
The examination of social impacts focuses on the involvement of the community, integration and interaction, which must be incorporated into the process of event organisation (pursuant to Shone and Parry 2004, Bowdin et al. 2006, Yeoman et al. 2004, Bull and Lovell 2007) ${ }^{1}$. In reference to the impacts identified by Shone \& Parry (2004: 54), this means the creation of better social interaction, helping to develop community cohesion, increasing cultural and social understanding and improving the community's identity and confidence in itself. Bull and Lowell (2007) reviewed the relevant studies written on residents' perception of sport events, which also mention these social impacts (Ohmann et al. 2006, Cegielski and Mules 2002). The review of Ohmann et al. (2006), and then that of the works of various authors (Hall 1992, Fredline 2005, Getz 1991, Higham 1999, Ritchie 1984), provides a comprehensive list of the concrete social impacts. It highlights the demonstration effect of community building, pride, the increased involvement of individuals in community activities, entertainment possibilities, as well as fitness and health as a positive impact. On the other hand, negative impacts, such as antisocial behaviour, crime, overloading, mass breakdown, disruptions to community life, alienation of the community and displacement are also listed. (Bull and Lovell 2007)

One of the conclusions of the analysis of the social impacts of non-mega sport events is that non-mega events are intended to encourage the whole population to be more physically active. The second finding is that inspiration varies across different population segments and across different types of events, when considering the legacy dimension of the inspiration effect, namely any subsequent change in sports participation behaviour (rather than immediate attitudinal change) as a result of attending /watching a major, but not mega, sport event (Ramchandani et al. 2015). The question is whether there is transition between the inspiration derived from attending an event and subsequent changes in sports participation behaviour. Examination was carried out to determine the longevity of such behavioural changes and their attribution to event attendance. The evidence from this research indicates that non-mega sport events have the potential to contribute to increases in participation by those who attend them. (Ramchandi et al 2015).

\section{Material and Methodology}

\section{Material - International Sport Events in Györ}

The city of Györ is home to several teams and successful individual athletes that rank high in national competitions. Consequently, the city's share in the sport economy can be considered outstandingly high at national level. The city is committed to supporting both professional and recreational sports, in other words to turning the residents into active and passive sport consumers.

\footnotetext{
${ }^{1}$ In their study Chris Bull and Jane Lovell discuss in detail the social impacts, and they reach the above conclusion starting out from the handbook on event management (Shone and Parry 2004, Bowdin et al. 2006, Yeoman et al. 2004).
} 
EYOF is an eight-day event with the participation of 3,600 official delegates (athletes and officials accompanying the teams) from 50 countries. The sport competitions are advertised for 14 to 18 year-old athletes in ten Olympic sports (athletics, cycling, gymnastics, judo, tennis, basketball, handball, volleyball, kayaking and canoeing). Hungary has participated in all EYOF events that have been organised since 1991. In terms of size, EYOF is similar to the winter Olympic Games and is entitled to use the protected Olympic symbols such as the Olympic rings, the anthem and the flag.

As a drive for urban development and a catalyst for several construction projects EYOF opened up new possibilities for the city of Györ. World class sport facilities (swimming pool, arena, indoor tennis court, Olympic Sport Park) were built. The construction of the Olympic Centre triggered the rehabilitation of an entire district of the city. Implementation of the international sport event was supported by the state, which included financial support. This created the possibility to implement construction projects - required irrespective of the sport event - with an added objective and adequate funding. In terms of the development of a host city, the implementation of sport facilities and infrastructure developments is of great importance and plays a key role in relation to the longterm legacy of the social impacts of international sport events.

The reason behind this is that the project is outstanding in terms of resources, and the question of post-utilisation of the facilities is of key importance when assessing the overall impacts. Today the judgement of construction projects related to international sport events depends on the success of post-utilisation, for which we can see both positive and negative examples. The goal in any case is sustainability, $100 \%$ long-term utilisation of the facilities, as well as the optimisation of operation. The goal is to enable the residents of the city to use the given facilities for a long time, and to encourage more and more people to be more physically active by creating the conditions for engaging in sport.

The need for sport infrastructure development can arise in many ways as a result of various inputs and initiatives. In relation to Györ one can distinguish three cases.

The first case involves infrastructure development carried out within the frameworks of international sport events, when the country/city does not have the facilities and infrastructure required for the event to be hosted, and the development projects are carried out in connection with this event (Györ, EYOF 2017).

In the second case, the need for such a project is triggered by an existing high standard sport facility and the growth in sport consumption (Audi Arena Györ, or the results of the Györ based women's handball club /Györi ETO KC/ in the EHF Champions League).

In the third case the lack of and need for the construction of a new facility arises in connection with the general sport development strategy of a given country or city, as well as the promotion of recreational sport and the development of junior athletes (AQUA Sport Centre, Györ). In the strategic concept of Györ these three factors, the simultaneous existence of all three types of needs can ensure highly stable and versatile utilisation and long-term sustainability. 
It can be generally claimed that the most important decision factor when considering the implementation of a sport infrastructure project should be the possibility of long-term utilisation. The essence of the project is timing and complex planning for long-term utilisation; linking the existing needs and interests to the arising possibilities.

We cannot disregard the case in which a city would implement the development projects irrespective of the sport event, but while looking for the most advantageous position, it links the development to the organisation of a sport event, and wins central financial support. Timing can be implemented in two ways: the implementation of the development projects must either be brought forward or put on hold until they can be linked to a sport event.

This study links the legacy of the international sport event, i.e. the sport facilities with the major segment of social impacts, i.e. the encouragement of sports and engagement in sport activities, the encouragement of the sport industry by sport events, including especially participation in sport activities.

\section{Method}

When planning the research process, I selected both qualitative and quantitative methods described in the international literature, those that matched the research topic best.

As a first step, my objective was to study the international literature, focusing on the social impacts. In the theoretical part of the study I provided a synthesis of the literature. I summarised the works of authors discussing the social impacts of international sport events.

In the qualitative research stage I applied the methods of observation, smallgroup discussions and professional interviews. In the quantitative research stage I applied a nonparametric test.

Questionnaire survey. In the questionnaire respondents evaluated 41 positive and negative statements under the attitude questions on the five-point Likert scale. The questionnaire, which was compiled on the basis of samples taken from literature, contained the following groups of questions. Economic contribution including tourism - Infrastructure development and attraction of investments in the sports industry - Financial burden and the problem of unutilised capacities - Social interaction - Transport related experience (instead of the impacts of traffic congestions) - Environmental damage - Inspiration by the sport culture. I posted the questionnaire online with the help of the Qualtrics programme.

I assigned 22 days for the completion of the pre-event questionnaire between 1 and 22 July 2017; 806 questionnaires were fully completed. As far as the postevent questionnaire is concerned, 703 questionnaires were completed in full during the 21 days between 1 and 21 August 2017. The respondents were Györ residents or people whose daily life and work linked them to Györ. I analysed the quantitative data using the IBM SPSS Statistics 22 programme. 


\section{Findings/Results}

\section{Findings of the Small-Group Discussion}

The small-group discussion as a method was conducted as a result of the fact that during the distribution of the questionnaire several of Györ's residents indicated via e-mail or comments that they would be ready to share with me their experience and observations.

What participants considered as the most important social impact of the sport event was the positive impact on children and their parents. During EYOF, Györ could witness the birth of role models in sport and general conduct. Participants attributed the greatest significance to those impacts of the event that "stick with young people", such as positive experience, openness, pride, sense of togetherness, since youth is the future asset of Györ.

In connection with the infrastructural legacy of EYOF, the biggest issue is the availability of competent human resources for the long-term utilisation of the facilities. Are there enough qualified and motivated sport professionals (PE teachers, coaches, sport managers) in Győr who will be able to fill these facilities? Gymnastics, judo or wrestling are sports that may revive or take root in the city thanks to the momentum generated by EYOF. Participants believe that due to its economic strength the city will be able to maintain and operate the newly built facilities in the long run. Special emphasis was placed on the role of the university and the reinforcement of this role through the development of student residence halls. On the other hand, the infrastructural project was criticized for the insufficient number of hotel rooms, which can significantly restrict the development of the tourist industry in Györ, including especially the number of sport travellers in the future.

In connection with the involvement of the local residents, the volunteer participating in the discussion claimed that volunteering provided the highest level of participation for those who really wanted to be actively involved in EYOF. The opportunity mostly appealed to people fewer than 30 and over 50 years of age. Volunteering allowed people to experience the positive experience of the knowledge of foreign languages, the opportunity to establish relationships and the inspiring international environment.

\section{Professional Interviews and Their Results}

I conducted a professional interview with Dr. Eszter Domanyik, head of the Department of City, City Marketing and Program Organisation of Györ, City with county rights, member of the organisational committee of the EYOF, in order to collect direct information from the perspective of Györ. As a result of the interview, I was able to identify the strategic plans of the host city, the actions aimed at the involvement of the population, as well as the areas linked to the development possibilities of international sport events.

I also contacted Csaba Simon, managing director of Györ Projekt Kft., head of the local government owned company responsible for the implementation of the 
sport facility, to conduct a professional interview with him. The results of the interview can be grouped around two topics: the strategic plans of the city on the one hand, and the long-term utilization of the hard legacy, i.e. the sport facilities on the other.

\section{Major Results}

After winning the right to host this international sport event, the city renewed its sport concept. In addition to the development of EYOF sports, the development of individual sports was also put into focus in the city that had previously centred on team sport, so that individual athletes training in Györ could also achieve successes at EYOF. Great emphasis was placed on the development of junior athletes in order to create a wide mass base for the sports included in the event.

The city organised several actions for the large-scale involvement of residents. In line with the practice applied in connection with the Audi Arena, which opened in 2014, according to which a sport facility can be used in a versatile manner, and it can offer residents multiple services, events, entertainment, and thus attract the population, a similar approach was chosen in relation to EYOF too. One of the success criteria defined was the persuasion of residents to be involved as much as possible. To this end several actions were implemented (mascot, reachout programs for all generations from nursery school children to senior citizens, torch run, community programs during the event). The involvement of the population was one of the key strategic objectives, because according to the concept this would allow us to achieve the social impacts of the events and to preserve them in the long run.

The cornerstone of the facility development strategy was that the sport facilities were built not for EYOF but for post-utilization purposes. The international sport event was an opportunity, a means for financing these projects.

Some of the sport facilities, as well as the concepts for the Aqua Sports Centre and Olympic Park had existed before Györ won the right to host EYOF, however construction was hindered by the lack of funds. The international sport event provided an opportunity for the implementation of the necessary projects.

The hard legacy is the long-term utilization of the sport facilities. In the case of the sport facilities that were constructed, the following post-utilization objectives were set during the strategic planning phase. The primary objective was to have adequate facilities for the development of junior athletes. The second objective was the provision of services for adult, professional athletes, both for locals and those participating in training camps organized in the city. In the case of the Olympic Sport Park several rental agreements have been signed with sport clubs, since the goal is to provide access to the facility to as many people as possible depending on capacity. The objective is to make the sites available not only for groups and teams, but also for recreational athletes pursuing individual's sports. The running tracks of OSP are open for the general public in the evenings, and after a few months of operation it can be claimed that OSP has become a favorite place for local recreational athletes and joggers. 


\section{Results of the Questionnaire Based Research}

To analyse the results, for the descriptive and explanatory procedures alike I used complex weighting procedures for both questionnaires to preserve the representative nature ex post. Therefore, the results can be generalised for the base population. Weighting referred to three dimensions - gender, age, level of education - for the comparison of the sample and the population ratios.

The consolidated database contained 1,337 individual cases, in which I created 16 consolidated variables. I used descriptive statistics for the analysis of these variables, and applied the weight created for the consolidated database. The responses to the questions pertaining to engagement in sport clearly show that over $50 \%$ of the local residents did sport for over 5 years as a child (Table 2 ), and $50 \%$ of them engage in sport activities on a weekly basis or more frequently even today (Table 3).

Table 2. Length of Engagement in Sport as a Child According To the Consolidated Database for Györ Residents (\%)

\begin{tabular}{|l|c|c|}
\hline For how many years did you do sport as a child? \\
\hline 0 to 1 year & $\mathrm{n}$ & $\%$ \\
\hline 1 to 3 years & 38 & 2,833 \\
\hline 4 to 5 years & 206 & 15,412 \\
\hline over 5 years & 208 & 15,530 \\
\hline I did not do any sport & 671 & 50,213 \\
\hline Total & 214 & 16,012 \\
\hline
\end{tabular}

Source: Author's research, Máté 2017.

Table 3. Current Frequency of Sport Activities of the Residents of Györ (\%)

\begin{tabular}{|l|c|c|}
\hline How often do you engage in sport now? & $\mathrm{n}$ & $\%$ \\
\hline Daily & 160 & 12.0 \\
\hline Several times a week & 326 & 24.4 \\
\hline Weekly & 179 & 13.4 \\
\hline Several times a month & 141 & 10.5 \\
\hline Monthly or less frequently & 252 & 18.9 \\
\hline Never & 279 & 20.8 \\
\hline Total & $\mathbf{1 3 3 7}$ & $\mathbf{1 0 0 . 0}$ \\
\hline
\end{tabular}

Source: Author's research, Máté 2017.

As far as sport consumption habits are concerned, it can be seen that nearly $50 \%$ of the residents of Györ regularly follow sport news in newspapers, on the radio or on TV. As many as $54.4 \%$ of them often watch sport broadcast. However, $49.1 \%$ of them never read any sport weekly or magazine.

As far as spectators' attendance at sport events is concerned, as much as $49.2 \%$ of the local residents have attended international sport events hosted by Győr. As many as $14.5 \%$ of them answered to our question regarding pastime activities that they often attend sport events in their free time. 
One of the basic questions regarding the general opinion about international sport events was whether the residents support Györ's pursuit in hosting international sport events in the future. This question attracted a positive response from $72.6 \%$ of the residents.

\section{Examination of Changes in Attitudes Using Panel Data}

With the help of the panel developed from respondents who completed both the pre- and post-event questionnaires I was able to examine changes and shifts in attitudes related to the effects of the sport event.

I conducted the comparison with the help of individual attitude variables the ordinal measurement of which required the application of a nonparametric test. Since the derived parameters of such variables can be examined only with reservations, nonparametric procedures that do not require the use of such variables can be used more reliably.

The primary objective when choosing the appropriate nonparametric procedure was the number and nature of the samples. Since in this case I had to study two related samples, I decided to apply the Wilcoxon test.

There is a significant shift in 16 of the 41 cases, always in the positive direction (Table 4).

In connection with transport and environmental impacts, a shift in perception can be observed in four and three statements, respectively. It can be assumed that the positive shifts can be attributed to the overestimation of the risks and the positive experience gained during the event. This assumption is reinforced by the fact that the statements pertain to things that are deeply imbedded in daily life and activities, therefore they are subject to continuous spontaneous observations.

In the case of social impacts the explanation behind the positive changes rests on similar facts, i.e. the residents underestimated or wrongly assessed the expected social impacts, and positively evaluated the actual experiences. However, the factors involved here have less to do with direct, everyday experiences, and can be summarised as follows:

- people do not deal with the issue, it is not an everyday issue

- it is not apparent, it is not in the focus

- it is rather abstract, it is more difficult to evaluate

- the latter statement is indicated by the fact that the percentage of missing responses is higher in the case of such questions

- personal experience can trigger a more significant shift in perception related to these factors

One can witness a positive change in connection to two statements related to sporting habits. In this case the more positive perception is triggered by involvement, personal experience gained at the event.

As far as negative impacts are concerned, the ex post perception of the event changed in a positive way in all but one statement. Negative statements regarding 
the economy and infrastructure also shifted in the positive direction. The underlying reason was the lack of experience or ideas about what the event may bring about if implemented. The only negative statement that did not significantly move in the positive direction is that the expenditures exceed the revenues of the event. This statement is difficult to judge empirically, since we cannot access additional information by studying the event alone.

In conclusion, out of the expected and actual impacts related to the international sport event, perception of impacts that could be experienced during the event changed in the positive directions, which was supported by the research findings.

Table 4. Variable Pair of the Social Impacts of an International Sport Event

\begin{tabular}{|l|c|c|c|c|c|c|c|c|c|}
\hline \multicolumn{1}{|c|}{ Variable pair } & \multicolumn{7}{|c|}{ Average } & \multicolumn{5}{|c|}{ Wilcoxon } \\
\cline { 2 - 9 } & pre & post & neg & pos & tie & Z & sig \\
\hline Positive statements & 3.10 & 3.39 & 31 & 70 & 71 & 3.786 & 0.000 \\
\hline $\begin{array}{l}\text { Leads to an enhanced sense of } \\
\text { community }\end{array}$ & 3.54 & 3.71 & 31 & 54 & 87 & 2.222 & 0.026 \\
\hline Leads to increased pride in the city & 3.48 & 3.87 & 28 & 75 & 69 & 4.167 & 0.000 \\
\hline Enhances the value of volunteering & 3.42 & 3.56 & 41 & 58 & 73 & 1.402 & 0.161 \\
\hline Boosts social life & 3.15 & 3.12 & 48 & 58 & 66 & -0.736 & 0.462 \\
\hline $\begin{array}{l}\text { Allows local residents to learn about } \\
\text { other cultures }\end{array}$ & 3.12 & 3.20 & 46 & 57 & 69 & 1.692 & 0.093 \\
\hline $\begin{array}{l}\text { Provides local residents with the } \\
\text { opportunity to establish international } \\
\text { relationships }\end{array}$ & 2.89 & 3.06 & 51 & 57 & 64 & 0.896 & 0.370 \\
\hline Drives local residents toward sport & 2.61 & 2.97 & 31 & 81 & 60 & 4.557 & 0.000 \\
\hline $\begin{array}{l}\text { Encourages local people to try new } \\
\text { sports }\end{array}$ & 3.34 & 3.47 & 36 & 48 & 88 & 0.767 & 0.473 \\
\hline $\begin{array}{l}\text { Encourages young people to engage } \\
\text { in sport }\end{array}$ & 2.42 & 2.65 & 28 & 67 & 77 & 3.711 & 0.000 \\
\hline $\begin{array}{l}\text { Improves the quality of life for local } \\
\text { residents }\end{array}$ & 3.09 & 3.20 & 39 & 51 & 82 & 1.078 & 0.281 \\
\hline $\begin{array}{l}\text { Improves sport culture and sport } \\
\text { awareness }\end{array}$ & 3.30 & 3.13 & 55 & 46 & 71 & -0.934 & 0.350 \\
\hline $\begin{array}{l}\text { Introduces new sports to local } \\
\text { residents }\end{array}$ & 2.80 & 2.95 & 39 & 55 & 79 & 1.399 & 0.162 \\
\hline $\begin{array}{l}\text { Encourages local residents to lead a } \\
\text { healthy lifestyle }\end{array}$ & & & & & \\
\hline
\end{tabular}

Source: Author's research, Máté 2017.

\section{Discussion}

The EYOF positively affected and strengthened people's good feelings and pride.

This study examines the social impacts of an international sport event, starting out from the definition of social impacts by Taks. According to Taks, social impacts mean changes in the collective and individual value systems, behaviour 
patterns, community structures, lifestyle and quality of life triggered by a sport event (Taks 2013).

To sum up, three main aspects of social impact can be identified. This study revealed results in terms of attitudes and beliefs, i.e. the degree to which sport events influence people's beliefs, attitudes, norms and values (e.g. pride, happiness, "feeling good");

The social impacts can be justified with the results and findings of the observation, small-group discussion and the questionnaire. The primary findings of the observation can be summarised as follows:

- Through the full house opening ceremony and through gathering by the giant screen in Dunakapu square, the residents of Györ bore witness to their interest in the international sport event. They put up effective demand for tickets to the opening ceremony.

- The key messages of the opening ceremony were the following: Sense of togetherness, we, the residents of Györ, form one family - We have done it together!

- The organisers implemented several actions to enable people to experience the sense of togetherness. This experience was facilitated by the 16,000 LED wristbands of PixMob. The ceremony was a real community experience for those sitting on the stands: the 16,000 wristbands that lit up synchronously were also interpreted as 16,000 hearts beating in unison.

- The presentation of Györ's cultural life and values gave spectators a real taste of the city. This programme allowed participants share proud looks and happy, carefree moments of entertainment.

- Athletes were often received by a full house at the competition venues. The popularity of the event was reflected by the large number of spectators $(80,000)$.

- Competitions in which Györ based athletes participated attracted even larger crowds.

- Richárd Sipőcz's success perfectly illustrates EYOF's goal: create shared experience, pride and happiness for residents, set smart, well-prepared, intelligent and talented role models for youth.

- People who attended the competitions and became involved in the flow of events could share the successes and experience the joy triggered by the remarkable successes, shiny medals and new role models that appeared thanks to the fantastic performances.

One of the messages of the small-group discussion also supports the hypothesis, according to which participants attributed the greatest significance to those impacts of the event that "stick with young people", such as positive experience, openness, pride, sense of togetherness, since youth is the future asset of Györ.

In addition to the shift in attitudes presented above based on the quantitative questionnaire, in the case of the responses to the attitude related questions, the 
average score of 10 statements on social impact out of the 13 showed a positive shift (Table 5) upon comparison of the pre- and post-event questionnaires.

Table 5. Changes in the Perception of Social Impacts in the Pre-and Post-Event Questionnaires

\begin{tabular}{|l|c|c|}
\hline Attitudes & Average score pre & $\begin{array}{c}\text { Average score } \\
\text { post }\end{array}$ \\
\hline Leads to an enhanced sense of community & 3.23 & 3.42 \\
\hline Leads to increased pride in the city & 3.63 & 3.71 \\
\hline Enhances the value of volunteering & 3.58 & 3.90 \\
\hline Boosts social life & 3.45 & 3.56 \\
\hline $\begin{array}{l}\text { Allows local residents to learn about other } \\
\text { cultures }\end{array}$ & 3.26 & 3.14 \\
\hline $\begin{array}{l}\text { Offers local residents the possibility to } \\
\text { establish international relationships }\end{array}$ & 3.23 & 3.20 \\
\hline Drives local residents toward sport & 3.01 & 3.06 \\
\hline $\begin{array}{l}\text { Encourages local residents to try new } \\
\text { sports }\end{array}$ & 2.70 & 2.96 \\
\hline $\begin{array}{l}\text { Encourages young people to engage in } \\
\text { sport activities }\end{array}$ & 3.39 & 3.45 \\
\hline $\begin{array}{l}\text { Improves the quality of life for local } \\
\text { residents }\end{array}$ & 2.53 & 2.67 \\
\hline $\begin{array}{l}\text { Improves sport culture and sport } \\
\text { awareness }\end{array}$ & 3.15 & 3.25 \\
\hline Introduces new sports to local residents & 3.28 & 3.09 \\
\hline $\begin{array}{l}\text { Encourages local residents to lead a } \\
\text { healthy life }\end{array}$ & 2.94 & 3.04 \\
\hline $\begin{array}{l}\text { Improves the quality of life for local } \\
\text { residents }\end{array}$ & 2.53 & 2.67 \\
\hline
\end{tabular}

Source: Own research, Máté 2017.

\section{Conclusions}

Based on the research findings it can be concluded that from among the expected and actual impacts of the EYOF, the impacts that could be actually experienced and lived through during the event were rather positive. EYOF positively influenced and reinforced people's "feeling good" state of mind and pride.

In the case of EYOF the host city did engage in strategic planning in order to further enhance the positive impacts. The strategic goals named increased involvement of local residents and making them committed to EYOF and increased links between urban development goals and EYOF have been achieved.

13 statements have been investigated as social impacts based on the feedbacks from inhabitants. The results of variable pairs in Wilcoxon test showed positive shift upon comparison of the pre- and post-event questionnaires:

Leads to an enhanced sense of community, leads to increased pride in the city, enhances the value of volunteering, encourages local people to try new sports, 
improves the quality of life for local residents. Especially should be emphasized the encourages of local people to try new sports.

Average score of 10 statements on social impact out of the 13 showed a positive shift upon comparison of the pre- and post-event questionnaires. In this topic 5 statements should emphasize: Drives local residents toward sport, Encourages local residents to try new sports, Encourages young people to engage in sport activities, Improves the quality of life for local residents, Improves sport culture and sport awareness.

\section{References}

András K, Kozma M (2014) The economic impacts of major international sports events. In Miklós Lukovics, Bence Zuti (eds) The dilemmas of territorial development.

Knott B, Swart K, Visser S (2015) The impact of sport mega-events on the quality of life for host city residents: Reflections on the 2010 FIFA World Cup African Journal of Hospitality. Tourism and Leisure 4 (Special edition). ISSN: 2223-814X.

Bowdin G, Allen J, O' Toole W, Harris R (2006) Events management, 2. Oxford: Elsevier.

Burnett C (2008) Assessing development of the 2010 Soccer World Cup. The impact of mega sport events on developmental goals. Invited speaker. University of Western Cape, Cape Town and Stellenbosch, Republic of South Africa, 5 - 7 March. Retrived from https://bit.ly/2MEP72W. [ Accessed March 2017].

Chain D (2009) Residents' perceptions of the 2010 FIFA World Cup: a case study of a suburb in Cape Town. South Africa CPUT Theses \& Dissertations. Paper 123. http://etd.cput.ac.za/bitstream/handle/20.500.11838/1582/198063318_Chain_dg_MT ech_thm_bus_2009.pdf?sequence=5\&isAllowed=y [Accessed March 2017].

Chalip L (2006) Towards social leverage of sport. Journal of Sport and Tourism 11(2): $109-127$.

Bull C, Lovell J (August 2007) The Impact of Hosting Major Sporting Events on Local Residents: an Analysis of the Views and Perceptions of Canterbury Residents in Relation to the Tour de France 2007. Journal of Sport Tourism 12 (3):229-248.

Cegielski M, Mules T (2002) Aspects of residents' perceptions of the GMC $400-$ Canberra's V8 Supercar Race. Current Issues in Tourism 5(1): 54-70.

Fredline E (2005) Host And Guest Relations And Sport Tourism. Sport In Society: Cultures, Commerce, Media, Politics 8(2): 263-279.

Getz D (1991) Festivals, special events, and tourism. London: Van Nostrand Reinhold International Company Limited.

Gyömörei T (2012) Regional sport structures: Sport management of municipalities in Hungary. PhD. dissertation in Hungarian.

Hall M (1992) Adventure, sport and health tourism. In Weiler B, Hall M (eds) Special interest tourism. London: Belhaven.

Higham J (1999) Sport as an avenue of tourism development: an analysis of the positive and negative impacts of sport tourism. Current Issues in Tourism 2(1): 82-90.

Kim SS, Petrick JF (2005) Residents' Perceptions on Impacts of the FIFA 2002 World Cup: The Case of Seoul as a Host City. Tourism Management 26: 25-38.

Máté T (2017) Nemzetközi sportrendezvény hatásainak a szervező város lakosai általi fogadtatása, észlelése és ezek jelentőségei - Az Európai Ifjúsági Olimpiai Fesztivál 2017 [The reception, perception and significance of the effects of an international sporting event by the residents of the organizing town - The European Youth 
Olympic Festival 2017]. Győr példáján keresztül - Doktori értekezés tervezet [Through Győr's example - Ph.D. dissertation draft]. Retrieved from https://bit.ly/ 2NP34zW.

Ramchandani G, Davies L, Coleman R, Shibli S, Bingham J (2015) Limited or lasting legacy? the effect of non-mega sport event attendance on participation. European Sport Management Quarterly 15 (1): 93-110.

Ritchie JRB (1984) Assessing the impact of hallmark events: conceptual and research issues. Journal of Travel Research 23 (1): 2-11.

Taks M (2013) Social sustainability of non-mega sport events in a global world. European Journal for Sport and Society 10 (2): 121-141.

Saayman M (2001) An introduction to sports tourism and event management. Potchefstroom: Leisure Consultants and Publications.

Shone A, Parry B (2004) Successful Events Management A Practical Handbook, 2. Thomson.

Ohmann S, Jones I, Wilkes K (2006) The Perceived Social Impacts Of The 2006 Football World Cup On Munich Residents. Journal of Sport \& Tourism 11(2): 129-152.

Yeoman I, Robertson M, Ali-Knight J, Drummond S, McMahon-Beattie U (2004) Festival and events management, an international arts and culture perspective. Elsevier Butterworth Heinemann. 
